\title{
Immunologic Markers of Progression to Acquired Immunodeficiency Syndrome are Time-Dependent and IIIness- Specific
}

\author{
Alexander Krämer, ${ }^{1}$ Robert J. Biggar, ${ }^{2}$ Hartmut Hampl, ${ }^{3}$ Robert M. Friedman, ${ }^{4}$ \\ Dietmar Fuchs, ${ }^{5}$ Helmut Wachter, ${ }^{5}$ and James J. Goedert ${ }^{2}$
}

Since prevalent cohorts may be biased by the duration of human immunodeficiency virus (HIV) infection (onset bias), it is useful to assess the potential predictive value of markers in incident cohorts of HIV-positive subjects for whom the date of seroconversion is known or can reliably be estimated. Of 131 homosexual men with HIV-1 seroconversion from New York City and Washington, DC, who were evaluated annually beginning in 1982, 60 developed acquired immunodeficiency syndrome (AIDS) by the end of 1989. The prognostic significance of immunologic markers (proportion of $\mathrm{CD} 4^{+} \mathrm{T}$-lymphocytes, neopterin, $\beta_{2}$-microglobulin, serum interferon, and anti-p24 antibody) and of a virologic marker (HIV p24 antigen) was determined using measurements made at defined time intervals after the known or estimated date of HIV seroconversion. When measurements made 3 years after seroconversion were used, all markers except anti-p24 antibody were found to be significant estimators of AIDS risk in univariate analyses. In multivariate Cox regression modeling, the maximum information was obtained by including neopterin, interferon, and the $\mathrm{CD}^{+}{ }^{+} \mathrm{T}$-lymphocyte proportion. The predictive value of markers after HIV seroconversion could change considerably from one interval to another. Elevated levels of $\beta_{2}$-microglobulin and neopterin significantly predicted the development of Kaposi's sarcoma. These two markers were highly correlated $(r=0.74)$. The authors conclude that immunologic markers can be important for an HIV staging system for estimating prognosis and facilitating early therapeutic intervention in HIV-positive patients. Am J Epidemiol 1992;136:71-80.

beta 2-microglobulin; HIV antibodies; HIV antigens; HIV-1; interferons; proportional hazards models; pteridines; T4 lymphocytes

The risk of developing acquired immunodeficiency syndrome (AIDS) among persons infected by the human immunodeficiency virus (HIV) can be estimated by a variety of immunologic and virologic markers, such as the $\mathrm{CD} 4^{+} \mathrm{T}$-lymphocyte count, urinary or serum neopterin, $\beta_{2}$-microglobulin, interferon, soluble interleukin-2 recep-
Received for publication August 8, 1991, and in final form December 2, 1991.

Abbreviations: AIDS, acquired immunodeficiency syndrome; HIV, human immunodeficiency virus; IU, internatıonal units; $\beta$, regression coefficient.

${ }^{1}$ Institute of Medical Biometry, University of Tübıngen, Tübıngen, Germany.

${ }^{2}$ Viral Epıdemıology Section, Natıonal Cancer Institute, Rockville, MD

${ }^{3}$ Abbott Diagnostics Products $\mathrm{GmbH}, \quad W-6200$ Wiesbaden-Delkenheim, Germany.

${ }^{4}$ Department of Pathology, Uniformed Services of the Health Sciences, Bethesda, MD.

${ }^{5}$ Institute of Medical Chemistry and Biochemistry, Innsbruck University, Innsbruck, Austria.

Reprint requests to Dr. James J. Goedert, Viral Epide- miology Section, National Cancer Institute, National Institutes of Health, Bullding EPN, Room 434, 6130 Executive Blvd., Rockville, MD 20852.

This work was supported by a grant from the American Foundation for AIDS Research (no 001077-7-RGD) to Dr. Friedman, and by a contract (no. N01-CP-61013) from the National Cancer Institute with the Research Triangle Institute.

We are grateful to Ms. Sue Felton and to Ms. Ginga Colclough, R.N., F.N.P., for study management and to Ms. Susan Wilson, Dr. Frances Yellin, and Ms. Karen Malley for expert computer programming. We are indebted to Drs. D. Schenzle and K. Dietz of Tübingen University and to Dr. M. H. Gail of the National Cancer Institute for fruitful discussions of the manuscript. 
tors, presence of HIV p24 antigen, and antibodies to p24 or gp120 (1-7). We have recently shown that the levels of some immunologic markers may significantly predict the risk of developing AIDS as early as 5 years before diagnosis (8). To assess the absolute risk of the development of AIDS in an HIV-1 seropositive individual, we prospectively evaluated immunologic and virologic markers of AIDS in HIV-positive homosexual men using actuarial methods. As studies of prevalently seropositive subjects are potentially biased because the duration of HIV-infection is unknown (onset bias) (9), markers were analyzed in relation to the known or estimated time of HIV seroconversion.

\section{MATERIALS AND METHODS}

\section{Subjects and study design}

Of 131 HIV-1 seropositive homosexual men evaluated approximately annually since 1982 (1), 60 had developed AIDS by the end of 1989. A seroconversion date, defined as the midpoint between the last negative and first positive sample, was available for 47 of the 131 infected men. For the 84 men already infected at the onset of the study, seroconversion dates were estimated using the method of backcalculation to develop regional norms. The average date of seroconversion for men in New York who were seropositive in 1982 was probably June 1980; for those in Washington, DC, it was probably June 1981 (10). To check the reliability of this approach, the annual and cumulative AIDS incidence rates using these imputed seroconversion dates were examined and found to be very similar to those of subjects in the same cohort with midpoint seroconversion dates (8).

\section{Laboratory assays}

HIV-1 antibodies were determined by a commercial enzyme-linked immunosorbent assay (Electronucleonics Inc., Columbia, $\mathrm{MD}$ ), and reactive samples were confirmed by Western blot analysis (Biotech Inc., Rockville, MD). The relative proportion of
$\mathrm{CD}^{+} \mathrm{T}$-lymphocytes was measured in lymphocytes that had been frozen and thawed using a fluorescence-activated cell sorter and OKT4 monoclonal antibodies (Ortho Diagnostics Co., Raritan, NJ). Serum neopterin was retrospectively measured by radioimmunoassay (Neopterin RIAcid, Henning-Berlin, Berlin, Germany), and $\beta_{2}$ microglobulin was measured in serum using double-antibody radioimmunoassay $\left(\beta_{2}\right.$ micro RIA, Pharmacia, Uppsala, Sweden). Serum interferon was measured in 96-well microtiter plates with the use of human FS4 fibroblasts; a challenge was performed with the encephalomyocarditis virus, as described elsewhere (11). A level of $>4$ international units (IU) was considered positive. HIV-1 p24 antigen was determined with a commercial enzyme-linked immunosorbent assay (Abbott Laboratories, North Chicago, IL). For confirmation of antigen positivity, an HIV-1 p24 neutralization test was performed. Anti-p24 antibodies were also determined using an enzyme-linked immunosorbent assay (Abbott Laboratories). For the determination of anti-p24 antibody titers, an anti-p24 quantitation assay (Abbott Laboratories) was used in accordance with the manufacturer's specifications. Potentially prognostic laboratory markers were measured sequentially at defined time intervals after HIV seroconversion. These intervals were defined in years ( \pm 6 months) from the date of seroconversion.

\section{Statistical analysis}

The method of Kaplan and Meier (12) was used to estimate AIDS-free survival. For this analysis, the markers were divided into approximate terciles, or analyzed in a dichotomous fashion with the categories absent or present. For comparison of KaplanMeier curves, log-rank statistics were calculated. Cox's proportional hazards model (13) was used to assess the predictive value of the covariates singly and in combination. Generally, the covariates were treated as continuous variables-CD4 ${ }^{+} \mathrm{T}$-lymphocyte proportion, neopterin, $\beta_{2}$-microglobulin, and anti-p24 antibodies-or as categorical vari- 
ables-HIV p24 antigen (absent/present) and interferon (absent/present). Interferon was coded as follows: code 0 (absent), <4 IU; codes $1-5$ (present)—code 1,4 to $<8$ IU; code 2,8 to $<12$ IU; code 3,12 to $<20$ IU; code 4, 20 to $<50$ IU; and code 5,>50 IU. A stepwise procedure was performed to determine the relative importance of the covariates in predicting the progression to AIDS. Since the proportion of $\mathrm{CD}^{+} \mathrm{T}$ lymphocytes has been well established as a predictive marker of AIDS, all bivariate and multivariate models included this variable.

Comparison and choice of models were based on their 2 log-likelihood estimates. For example, first, all possible univariate models were analyzed; second, all bivariate combinations including the proportion of $\mathrm{CD}^{+}$ T-lymphocytes at any rate were analyzed; then, third, the best bivariate model according to the 2 log-likelihood estimates was used as the basis for multivariate models with three combinations of markers. More elaborate models were not used, because the full model containing all possible variables did not improve the 2 log-likelihood estimate substantially above the level of three variables. These analyses were performed prospectively to estimate the relative hazard of AIDS following measurements taken at defined time intervals after HIV seroconversion. The time intervals 3 years after seroconversion, 4 years after seroconversion, 5 years after seroconversion, and after the level of $\mathrm{CD}^{+}$lymphocytes had dropped below $500 / \mathrm{ml}$ were chosen because there were sufficient complete sets of marker measurements for these intervals. Spearman rankorder correlation was used for calculation of correlation coefficients between markers.

\section{RESULTS}

\section{AIDS-free survival}

Complete sets of marker data were available for 81 of the 131 HIV-seropositive homosexual men; 36 of these 81 men developed AIDS during the observation period. Only data for the 81 subjects with complete sets of marker data were used in the Kaplan-
Meier analysis. As illustrated in KaplanMeier plots (figures 1-6), AIDS-free survival 3 years after HIV seroconversion differed at various levels for immunologic and virologic markers. This was significant for the $\mathrm{CD}^{+}$ T-lymphocyte proportion, neopterin, $\beta_{2}$ microglobulin, interferon, and HIV p24 antigen, but not for anti-p24 antibody ( $p=$ $0.06)$. For example, at 1,525 days (4.18 years), the AIDS-free survival in subjects with a $\mathrm{CD}^{+} \mathrm{T}$-lymphocyte proportion of $<25$ percent was zero; it was approximately 60 percent in subjects whose $\mathrm{CD}^{+} \mathrm{T}$ lymphocyte proportion was between 25 and 35 percent, and 70 percent for those whose $\mathrm{CD}^{+}{ }^{+}$T-lymphocyte proportion was $>35$ percent. At this same time interval, 77 percent of the subjects with neopterin levels of $<10 \mathrm{nmol} /$ liter were AIDS-free, compared with 56 percent of those with neopterin lev-

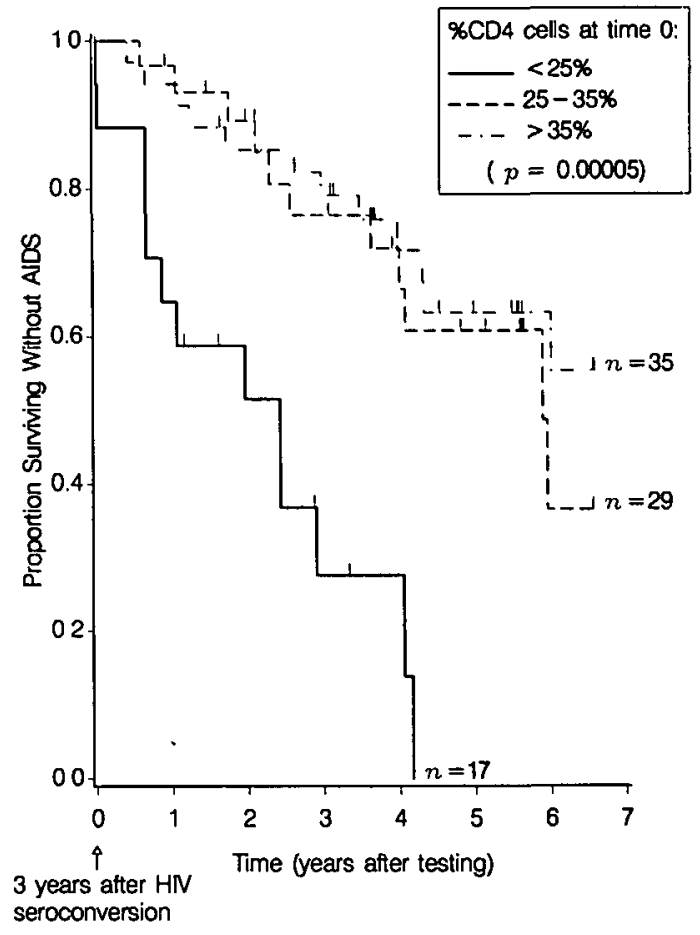

FIGURE 1. Kaplan-Meier plots of the proportion of subjects without AIDS by approximate tercile of the $\mathrm{CD4}^{+}$T-lymphocyte proportion 3 years after seroconversion. (Key: $n$, number of HIV-seropositive subjects without AIDS at time 0 ; vertical tick marks, subjects without AIDS who were censored; the $p$ value for the difference in disease-free survival was derived from the log-rank test). 


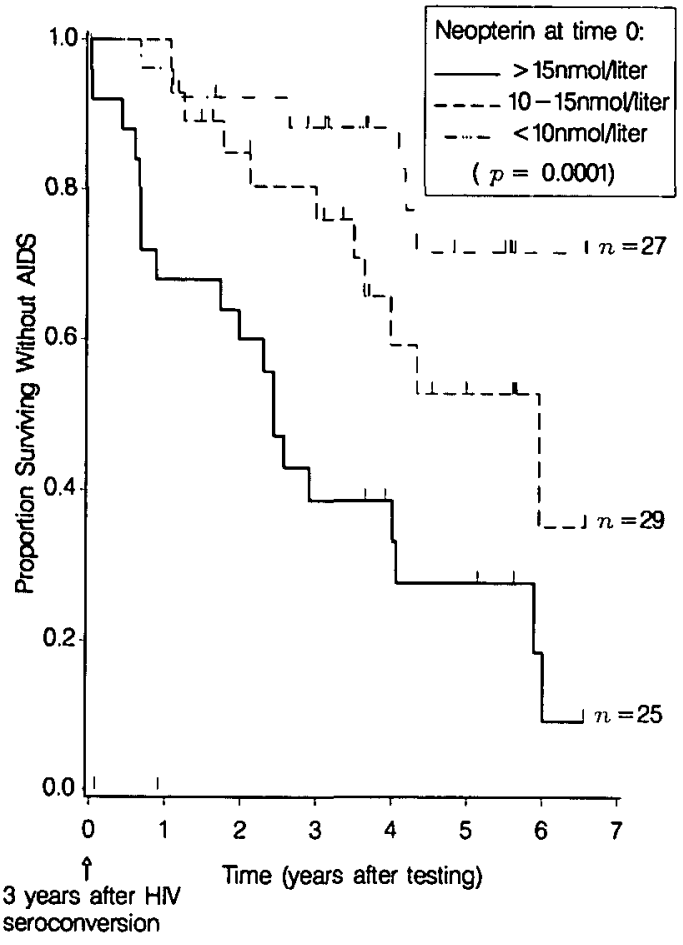

FIGURE 2. Kaplan-Meier plots of the proportion of subjects without AIDS by approximate tercile of serum neopterin 3 years after seroconversion. (Key: $n$, number of HIV-seropositive subjects without AIDS at time 0; vertical tick marks, subjects without AIDS who were censored; the $p$ value for the difference in disease-free survival was derived from the log-rank test).

els of 10-15 nmol/liter and only 26 percent of those with levels of $>15 \mathrm{nmol} /$ liter. With respect to serum interferon, AIDS-free survival was 0 after 2,154 days ( 5.9 years) when interferon was present, compared with about 53 percent when interferon had been absent. The interval of 3 years after seroconversion was chosen because the marker measurements were most complete at this interval.

\section{Proportional hazards models for AIDS}

Table 1 shows the results from univariate, bivariate, and multivariate analyses using proportional hazards models to assess the predictive value of the markers singly and in combination. Again, all markers except antip24 antibody proved to be single significant AIDS predictors. Bivariate and multivariate combinations are only displayed for models that include the proportion of $\mathrm{CD}^{+} \mathrm{T}$ lymphocytes, because the predictive poten-

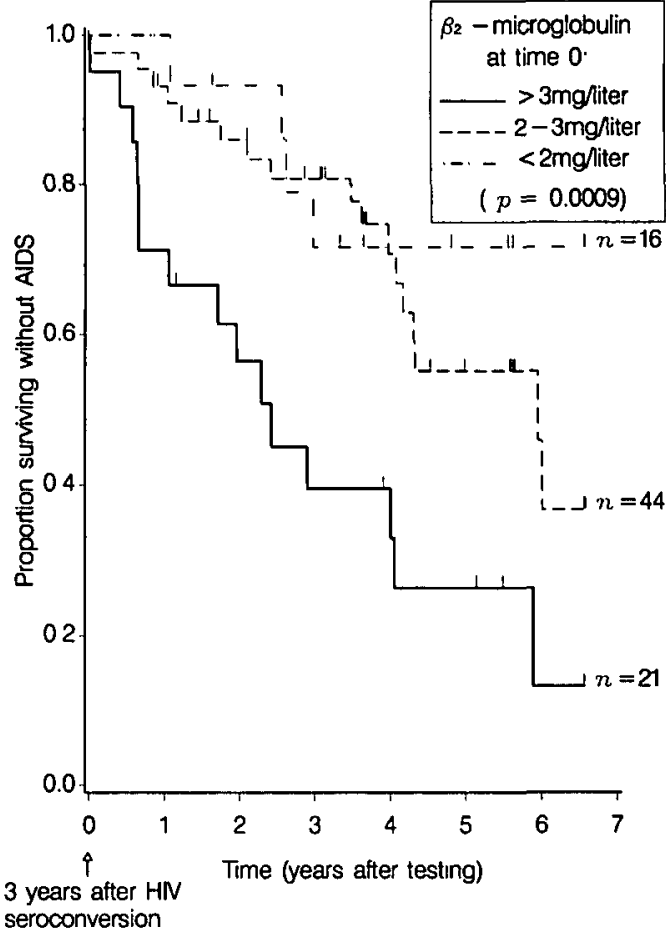

FIGURE 3. Kaplan-Meier plots of the proportion of subjects without AIDS by approximate tercile of $\beta_{2-}$ microglobulin 3 years after seroconversion. (Key: $n$, number of HIV-seropositive subjects without AIDS at time 0; vertical tick marks, subjects without AIDS who were censored; the $p$ value for the difference in diseasefree survival was derived from the log-rank test).

tial of this marker is beyond doubt. As illustrated by the $2 \log$-likelihood estimates, the model incorporating neopterin, interferon, and the $\mathrm{CD} 4^{+} \mathrm{T}$-lymphocyte proportion $(2$ log-likelihood $=-239.65$ ) was the best predictive model, resulting in the following hazard function equation:

$$
\begin{aligned}
\lambda(t) & =\lambda_{0}(t) \exp (0.0900 \text { neopterin } \\
& +0.4462 \text { interferon }-0.0221 \text { CD4\% })
\end{aligned}
$$

where CD4\% equals the relative proportion of $\mathrm{CD}^{+} \mathrm{T}$-lymphocytes. Compared with this model, the full model with all markers included did not add significant information: (difference in 2 log-likelihood: -238.45 $+239.65=1.2, p>0.2$ ).

In addition, we evaluated the prognostic potential of the markers as time-dependent variables. In other words, did the prognostic value of a given marker vary with measurements of this marker at different times in 


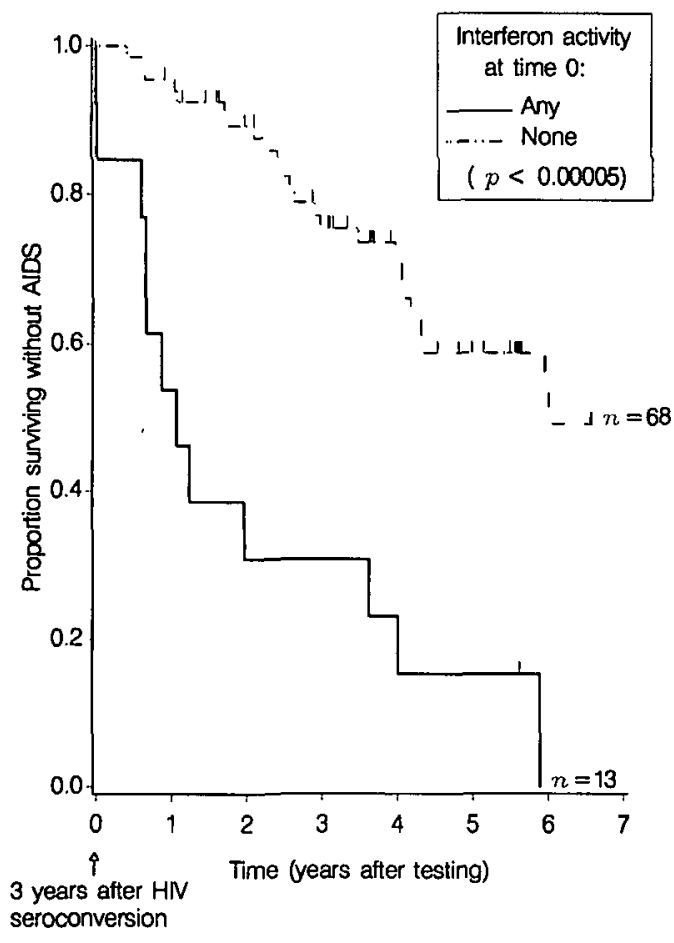

FIGURE 4. Kaplan-Mejer plots of the proportion of subjects without AIDS by the presence or absence of interferon 3 years after seroconversion. (Key: $n$, number of HIV-seropositive subjects without AIDS at time 0; vertical tick marks, subjects without AIDS who were censored; the $p$ value for the difference in disease-free survival was derived from the log-rank test).

the course of HIV disease? Therefore, we analyzed proportional hazards models for AIDS using as starting points measurements made at different times after HIV seroconversion and after $\mathrm{CD}^{+}$T-lymphocyte counts had dropped below $500 / \mathrm{ml}$. Table 2 displays beta coefficients and standard errors for the model incorporating the $\mathrm{CD} 4^{+} \mathrm{T}$ lymphocyte proportion, neopterin, and interferon at these various other intervals. One sees that the predictive value of markers can change considerably from one time interval to another. Prognostic models at different times after HIV seroconversion could, therefore, contain different combinations of markers (data not shown).

\section{Prognostic markers for the development of Kaposi's sarcoma}

In order to be specific for a given category of AIDS illness, we analyzed prognostic

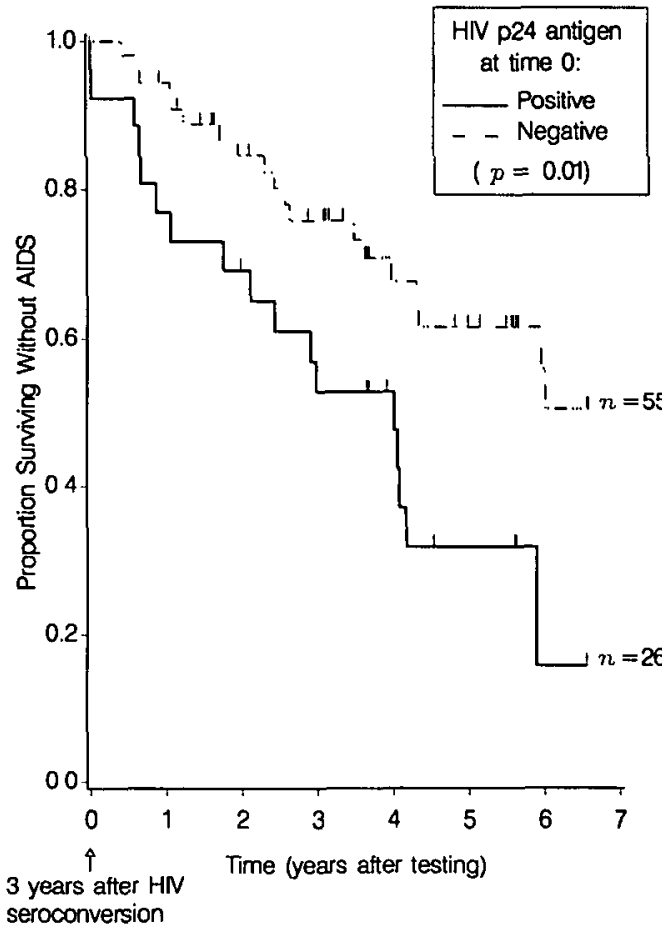

FIGURE 5. Kaplan-Meier plots of the proportion of subjects without AIDS by the presence or absence of HIV p24 antigen 3 years after seroconversion. (Key: $n$, number of HIV-seropositive subjects without AIDS at time 0; vertical tick marks, subjects without AIDS who were censored; the $p$ value for the difference in diseasefree survival was derived from the log-rank test).

markers in the subgroup of subjects whose only initial manifestation of AIDS was Kaposi's sarcoma as compared with markers in HIV-positive controls who did not develop AIDS during the study period. Since the data were sparse (11 cases), this analysis was performed in a univariate fashion only (table 3). Despite the small number of subjects, neopterin and $\beta_{2}$-microglobulin were both found to be significant predictors of Kaposi's sarcoma ( $p=0.0009$ and $p=$ 0.044 , respectively). Since opportunistic infections were the most frequent initial manifestation of AIDS ( 43 cases), the predictive markers for this illness category were very similar to those presented above for the entire group of AIDS patients.

\section{Correlations between markers}

Table 4 shows the correlations among the six markers from all measurements taken 3 


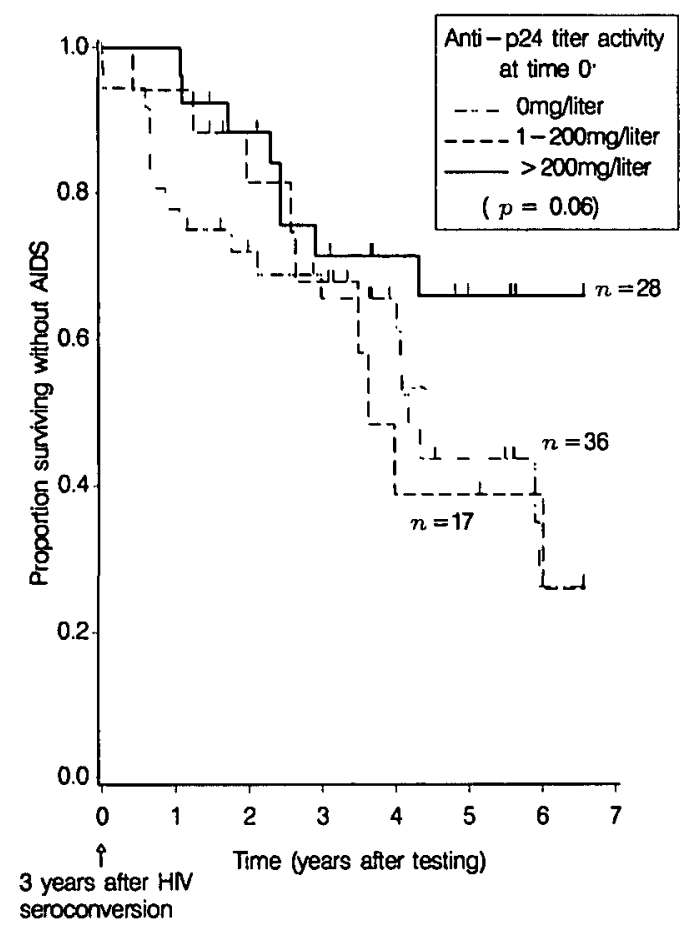

FIGURE 6. Kaplan-Meier plots of the proportion of subjects without AIDS by approximate tercile of antiHIV p24 antibody 3 years after seroconversion. (Key: $n$, number of HIV-seropositive subjects without AIDS at time 0 ; vertical tick marks, subjects without AIDS who were censored; the $p$ value for the difference in disease-free survival was derived from the log-rank test).

years after HIV seroconversion (Spearman rank-order correlation coefficients). In addition to anti-p24 antibody and p24 antigen ( $r=-0.59, p=0.0001$ ), $\beta_{2}$-microglobulin and neopterin were also very highly correlated $(r=0.74, p=0.0001)$.

\section{DISCUSSION}

We analyzed the potential of immunologic and virologic markers to predict AIDS in relation to HIV seroconversion, with measurements taken at different time intervals after seroconversion and before the onset of AIDS. When measurements made 3 years after HIV seroconversion were used, various immunologic markers (the proportion of $\mathrm{CD}^{+} \mathrm{T}$-lymphocytes, neopterin, $\beta_{2^{-}}$ microglobulin, and interferon) and p24 antigen were significant predictors of AIDS for the next 6 years, that is, up to the ninth year after HIV infection (figures 1-6). A proportional hazards model incorporating neopterin, interferon and the $\mathrm{CD}^{+} \mathrm{T}$ lymphocyte proportion had the best predictive value for progression of HIV-positive homosexual men to AIDS (table 1).

It was interesting that the prognostic value of markers could vary considerably during HIV disease (table 2). A marker may thus be a good predictor shortly after seroconversion but fail to estimate the subsequent risk of AIDS accurately when measured late in the course of HIV infection, or vice versa. Since the variation of estimates may partly be due to the sparse number of subjects, further studies with larger numbers are needed to obtain more precise estimates of the subsequent risk of AIDS for different intervals, and to characterize the exact pattern over time. Nonetheless, our findings clearly indicate that the predictive value of the markers is time-dependent. The following hazard function equation takes this timedependence into account:

$$
\begin{aligned}
\lambda(t)=\lambda_{0}(t) \exp \left[\beta_{1}(t) X_{1}+\right. & \beta_{2}(t) X_{2} \\
& \left.+\ldots+\beta_{\mathrm{i}}(t) X_{1}\right] .
\end{aligned}
$$

It should also be noted that longer time since HIV seroconversion was itself predictive of AIDS (data not shown), even in the full model.

We are aware that the date of HIV seroconversion of an HIV-seropositive individual is usually not known in the clinical setting. Therefore, one may conclude that the time-dependence with respect to the predictive value of AIDS progression markers is only of theoretical interest and of no practical importance. However, an approximate seroconversion date can be estimated for many persons with prevalent infections based on the history of specific exposures (e.g., rare anal intercourse, contact with a prostitute, or condom failure) or symptoms compatible with the HIV seroconversion syndrome that may occur in one quarter of all incident HIV infections.

In addition, one must be specific about the AIDS illness category: Markers of im- 
TABLE 1. Analyses of potential markers of progression to AIDS* using proportional hazards models $\uparrow$ with measurements made 3 years after HIV* seroconversion

\begin{tabular}{|c|c|c|c|c|}
\hline Proportional hazards model & $\beta \ddagger$ & SE§ & $p$ value & $\begin{array}{l}2 \text { Log- } \\
\text { likelihood }\end{array}$ \\
\hline Null model & & & & -277.16 \\
\hline \multicolumn{5}{|l|}{ Univariate models } \\
\hline CD4+ T-lymphocytes (\%) & -0.0519 & 0.0195 & 0.008 & -268.23 \\
\hline Neopterin (nmol/liter) & 0.1145 & 0.0240 & 0.0001 & -250.01 \\
\hline$\beta_{2}$-Microglobulin (mg/liter) & 0.7225 & 0.1687 & 0.0001 & -262.11 \\
\hline Interferon (codes 0-5) & 0.8172 & 0.1453 & 0.0001 & -253.86 \\
\hline HIV p24 antigen (0-1) & 0.8672 & 0.3384 & 0.01 & -270.85 \\
\hline Anti-p24 antibody (mg/liter) & -0.00002 & 0.00002 & 0.39 & -274.31 \\
\hline \multicolumn{5}{|l|}{ Bivariate models } \\
\hline $\begin{array}{l}\mathrm{CD}^{+} \text {T-lymphocytes (\%) } \\
\text { Neopterin (nmol/liter) }\end{array}$ & $\begin{array}{r}-0.0268 \\
0.1185\end{array}$ & $\begin{array}{l}0.0137 \\
0.0278\end{array}$ & $\begin{array}{l}0.05 \\
0.0001\end{array}$ & -244.25 \\
\hline $\begin{array}{l}\mathrm{CD4}^{+} \text {T-lymphocytes (\%) } \\
\beta_{2} \text {-Microglobulin (mg/iter) }\end{array}$ & $\begin{array}{r}-0.0304 \\
0.6259\end{array}$ & $\begin{array}{l}0.0185 \\
0.1827\end{array}$ & $\begin{array}{l}0.099 \\
0.0006\end{array}$ & -258.49 \\
\hline $\begin{array}{l}\mathrm{CD}^{+} \text {T-lymphocytes }(\%) \\
\text { interferon (codes } 0-5 \text { ) }\end{array}$ & $\begin{array}{r}-0.0313 \\
0.7214\end{array}$ & $\begin{array}{l}0.0184 \\
0.1536\end{array}$ & $\begin{array}{l}0.089 \\
0.0001\end{array}$ & -250.28 \\
\hline $\begin{array}{l}\mathrm{CD4}^{+} \text {T-lymphocytes (\%) } \\
\text { HIV p24 antigen }(0-1)\end{array}$ & $\begin{array}{r}-0.0399 \\
0.5077\end{array}$ & $\begin{array}{l}0.0210 \\
0.3757\end{array}$ & $\begin{array}{l}0.057 \\
0.18\end{array}$ & -266.42 \\
\hline $\begin{array}{l}\text { CD4 }{ }^{+} \text {T-lymphocytes (\%) } \\
\text { Anti-p24 antibody (mg/liter) }\end{array}$ & $\begin{array}{l}-0.0487 \\
-0.00002\end{array}$ & $\begin{array}{l}0.0194 \\
0.00002\end{array}$ & $\begin{array}{l}0.012 \\
0.42\end{array}$ & -266.30 \\
\hline $\begin{array}{l}\text { Multivariate models } \\
\text { CD4 } 4^{+} \text {T-lymphocytes (\%) } \\
\text { Neopterin (nmol/liter) } \\
\beta_{2} \text {-Microglobulin (mg/liter) }\end{array}$ & $\begin{array}{r}-0.0250 \\
0.1053 \\
0.1584\end{array}$ & $\begin{array}{l}0.0139 \\
0.0317 \\
0.2368\end{array}$ & $\begin{array}{l}0.072 \\
0.0009 \\
0.50\end{array}$ & -243.83 \\
\hline $\begin{array}{l}\text { CD4+ T-lymphocytes (\%) } \\
\text { Neopterin (nmol/liter) } \\
\text { Interferon (codes 0-5) }\end{array}$ & $\begin{array}{r}-0.0221 \\
0.0900 \\
0.4462\end{array}$ & $\begin{array}{l}0.0142 \\
0.0314 \\
0.1902\end{array}$ & $\begin{array}{l}0.12 \\
0.004 \\
0.019\end{array}$ & -239.65 \\
\hline $\begin{array}{l}\text { CD4+ T-lymphocytes (\%) } \\
\text { Neopterin (nmol/liter) } \\
\text { HIV p24 antigen }(0-1)\end{array}$ & $\begin{array}{r}-0.0261 \\
0.1173 \\
0.0512\end{array}$ & $\begin{array}{l}0.0146 \\
0.0293 \\
0.4019\end{array}$ & $\begin{array}{l}0.073 \\
0.0001 \\
0.90\end{array}$ & -244.24 \\
\hline $\begin{array}{l}\text { CD4 }{ }^{+} \text {T-lymphocytes (\%) } \\
\text { Neopterin (nmol/liter) } \\
\text { Anti-p24 antibody (mg/iter) }\end{array}$ & $\begin{array}{r}-0.0258 \\
0.1157 \\
-0.00001\end{array}$ & $\begin{array}{l}0.0135 \\
0.0274 \\
0.00002\end{array}$ & $\begin{array}{l}0.055 \\
0.0001 \\
0.49\end{array}$ & -243.01 \\
\hline \multicolumn{5}{|l|}{ Full model } \\
\hline $\begin{array}{l}\text { CD4 }^{+} \text {T-lymphocytes (\%) } \\
\text { Neopterin (nmol/liter) }\end{array}$ & $\begin{array}{r}-0.0214 \\
0.0843\end{array}$ & $\begin{array}{l}0.0150 \\
0.0365\end{array}$ & $\begin{array}{l}0.15 \\
0.021\end{array}$ & -238.45 \\
\hline$\beta_{2}$-Microglobulin (mg/liter) & 0.0615 & 0.2595 & 0.81 & \\
\hline Interferon (codes 0-5) & 0.4295 & 0.1989 & 0.031 & \\
\hline HIV p24 antigen (0-1) & 0.0674 & 0.4213 & 0.87 & \\
\hline Anti-p24 antibody (mg/liter) & -0.00001 & 0.00002 & 0.50 & \\
\hline
\end{tabular}

* AIDS, acquired immunodeficiency syndrome; HIV, human immunodeficiency virus.

† Note that models were built hierarchically upon the $\mathrm{CD4}^{+}$T-lymphocyte proportion because the predictive value of this marker is well established.

$\ddagger$ The regression coefficients refer to the units in parentheses next to the variables. For example, for the univariate model "CD4 ${ }^{+}$ T-lymphocytes," the coefficient represents a negative change of 0.0519 related to a unit percentage change in $C D 4^{+} T$-lymphocytes. For "Interferon (codes 0-5)," the coefficient is related to a change of one code, e.g., from 2 to 3, etc.

$\S \mathrm{SE}$, standard error of the regression coefficient.

mune system stimulation, neopterin and $\beta_{2^{-}}$ microglobulin, were significant predictors for Kaposi's sarcoma in our univariate anal- yses (table 3). This has already been suggested by a descriptive analysis of our cohort (14) and by another study (15). However, 
TABLE 2. Results of the proportional hazards model incorporating the $\mathrm{CD4}^{+} \mathrm{T}$-lymphocyte proportion, neopterin, and interferon at different times of HIV† disease

\begin{tabular}{|c|c|c|c|}
\hline Time of HIV disease & $\beta \ddagger$ & SE $\S$ & $p$ value \\
\hline \multicolumn{4}{|c|}{3 years after seroconversion $(n=81)$} \\
\hline $\mathrm{CD}^{+}$T-lymphocytes (\%) & -0.0221 & 0.0142 & 0.12 \\
\hline Neopterin (nmol/liter) & 0.0900 & 0.0314 & 0.004 \\
\hline Interferon (codes $0-5$ ) & 0.4462 & 0.1902 & 0.019 \\
\hline \multicolumn{4}{|c|}{4 years after seroconversion $(n=65)$} \\
\hline CD4+ T-lymphocytes (\%) & $-0.0593^{*}$ & 0.0235 & 0.01 \\
\hline Neopterin (nmol/liter) & 0.0539 & 0.0397 & 0.17 \\
\hline Interferon (codes 0-5) & 0.2457 & 0.1857 & 0.19 \\
\hline \multicolumn{4}{|c|}{5 years after seroconversion $(n=49)$} \\
\hline $\mathrm{CD}^{+}$T-lymphocytes (\%) & -0.0594 & 0.0337 & 0.078 \\
\hline Neopterin (nmol/liter) & 0.0800 & 0.0313 & 0.01 \\
\hline Interferon (codes $0-5$ ) & 0.5178 & 0.1914 & 0.007 \\
\hline \multicolumn{4}{|c|}{$<500 \mathrm{CD}^{+}$T-lymphocytes $/ \mu \mathrm{l}(n=76)$} \\
\hline $\mathrm{CD4}^{+} \mathrm{T}$-lymphocytes (\%) & $-0.0920^{* *}$ & 0.0244 & 0.0002 \\
\hline Neopterin (nmol/liter) & 0.0487 & 0.0249 & 0.05 \\
\hline Interferon (codes 0-5) & $0.0597^{* * *}$ & 0.1332 & 0.65 \\
\hline
\end{tabular}

since the number of subjects was sparse, other markers, such as the $\mathrm{CD}^{+} \mathrm{T}$ lymphocyte proportion, may also become significant predictors of Kaposi's sarcoma with a larger number of subjects.

The results reported here are in agreement with our earlier findings that significant changes in the $\mathrm{CD}^{+}{ }^{+} \mathrm{T}$-lymphocyte proportion, neopterin, and $\beta_{2}$-microglobulin occurred within 1-2 years after seroconversion in subjects who developed AIDS during the study period (8). They are also in agreement with our report from early in the HIV epidemic that serum interferon activity predicted AIDS in subjects with hemophilia (16) and with reports from other investigators who found elevated neopterin and $\beta_{2^{-}}$ microglobulin levels early in HIV infection (17-19). Recently, we were able to demonstrate that the risk of AIDS can be predicted with immunologic markers as early as even 1 year after HIV seroconversion (20), which supports the observation that events occurring soon after or around seroconversion influence the progression to AIDS (21). Understanding the pathogenesis of immunologically severe HIV seroconversions may pro- vide therapeutic opportunities to reduce the risk of AIDS further.

In our analysis, immunologic markers were superior to HIV p24 antigen in their potential to predict progression to AIDS. Neopterin is a compound of low molecular weight derived from dihydroneopterintriphosphate, an intermediate in the de novo synthesis of tetrahydrobiopterin from guanosine triphosphate. Neopterin was found to be present in high concentrations in supernatants of mixed cultures of mononuclear cells from human peripheral blood and of monocytes and macrophages stimulated by $\gamma$-interferon (22). $\beta_{2}$-Microglobulin is a protein of low molecular weight that is present on the surface of all nucleated cells as the constant subunit of class I histocompatibility antigens (23). Most of the interferon activity that we detected was $\alpha$-interferon, although complete formal characterization has not been done (7). Mononuclear cells, including monocytes, natural killer cells, and Blymphocytes, produce $\alpha$-interferon in response to infections with viruses, other intracellular organisms, and other inducers (24). Although the specific inducer or induc- 
TABLE 3. Univariate analyses of markers in HIV*-seropositive subjects whose only initial manifestation of AIDS* was Kaposi's sarcoma

\begin{tabular}{lcccc}
\hline & $\beta \dagger$ & SE & $\rho$ value & $\begin{array}{c}2 \text { Log- } \\
\text { likelihood }\end{array}$ \\
\hline Null model & & & -64.70 \\
Univariate models & & & \\
CD4+ T-lymphocytes (\%) & 0.0105 & 0.0404 & 0.8 & -64.63 \\
Neopterin (nmol/liter) & 0.2456 & 0.0738 & 0.0009 & -53.55 \\
$\beta_{2}$-Microglobulin (mg/liter) & 1.2035 & 0.5967 & 0.044 & -60.72 \\
Interferon (codes 0-5) & 0.0204 & 0.4973 & 0.97 & -64.70 \\
HIV p24 antigen (0-1) & -0.6197 & 1.0698 & 0.56 & -64.31 \\
Anti-p24 antibody (mg/liter) & \multicolumn{4}{c}{ (no convergence) } \\
\hline
\end{tabular}

*HIV, human immunodeficiency virus; AIDS, acquired immunodeficiency syndrome.

t The regression coefficients refer to the units in parentheses next to the variables.

$¥ \mathrm{SE}$, standard error of the regression coefficient.

TABLE 4. Spearman rank order correlations of markers of progression to AIDS* based on measurements made 3 years after HIV* seroconversion

\begin{tabular}{|c|c|c|c|c|c|}
\hline & $\mathrm{CD} 4 \% \dagger$ & Neopterin & $\beta_{2}$-Microglobulin & Interferon & $\begin{array}{c}\text { p24 } \\
\text { Antigen }\end{array}$ \\
\hline Neopterin & -0.48 & & & & \\
\hline$\beta_{2}$-Microglobulin & -0.48 & 0.74 & & & \\
\hline Interferon & -0.35 & 0.42 & 0.38 & & \\
\hline p24 Antigen & -0.45 & 0.41 & 0.33 & 0.29 & \\
\hline Anti-p24 antibody & 0.28 & -0.31 & -0.28 & -0.23 & -0.59 \\
\hline
\end{tabular}

* AIDS, acquired immunodeficiency syndrome; HIV, human immunodeficiency virus.

† Proportion of CD4 ${ }^{+}$T-lymphocytes

ers of neopterin, $\beta_{2}$-microglobulin, and interferon have not been defined, these serum proteins are products of immunostimulation. Their roles in elucidating the pathogenesis of AIDS have not yet been precisely defined.

The Centers for Disease Control classification system provides a clinical basis for case definition (25) but does not characterize the degree of illness, pathobiology, or prognosis. On the other hand, the "Walter Reed staging classification for HTLV-III/LAV infection" (26) characterizes the progressive nature of the pathobiology and is prognostic. However, the Walter-Reed system requires not only a physical examination and T-cell testing but also delayed hypersensitivity testing with a battery of skin test antigens that must be read by trained personnel 48 hours after application. Our data suggest that a combination of immunologic markers, including the $\mathrm{CD}^{+}{ }^{+} \mathrm{T}$-lymphocyte proportion, neopterin or $\beta_{2}$-microglobulin, and serum interferon might provide a convenient alter- native method of assessing prognosis in HIV-positive individuals. These serological tests are relatively inexpensive by Western medical standards, with costs in the range of a standard HIV antibody test. Since neopterin and $\beta_{2}$-microglobulin are very highly correlated (table 4), it may be sufficient to determine only one of these two markers.

\section{REFERENCES}

1. Goedert JJ, Biggar RJ, Melbye M, et al. Effect of T4 count and cofactors on the incidence of AIDS in homosexual men infected with human immunodeficiency virus. JAMA 1987;257:331-4.

2. Bogner JR, Matuschke A, Heinrich B, et al. Serum neopterin levels as predictors of AIDS. Klin Wochenschr 1988;66:1015-18.

3. Krämer A, Wiktor SZ, Fuchs D, et al. Neopterin: a predictive marker of acquired immune deficiency syndrome in human immunodeficiency virus infection. J Acquir Immune Defic Syndr 1989;2: 291-6.

4. Eyster ME, Ballard JO, Gail $\mathrm{MH}$, et al. Predictive markers for the acquired immunodeficiency syn- 
drome (AIDS) in hemophiliacs: persistence of $p 24$ antigen and low T4 cell count. Ann Intern Med 1989;110:963-9.

5. Moss AR, Bacchetti P, Osmond D, et al. Seropositivity for HIV and the development of AIDS or AIDS related condition: three year follow up of the San Francisco General Hospital cohort. BMJ 1988; 296:745-50.

6. Fahey JL, Taylor JMG, Detels $\mathbf{R}$, et al. The prognostic value of cellular and serologic markers in infection with human immunodeficiency virus type 1. N Engl J Med 1990;322:166-72.

7. Goedert JJ, Kessler CM, Aledort LM, et al. A prospective study of human immunodeficiency virus type 1 infection and the development of AIDS in subjects with hemophilia. N Engl J Med 1989; 321:1141-8.

8. Krämer A, Biggar RJ, Fuchs $D$, et al: Levels of $\mathrm{CD}_{4}^{+}$lymphocytes, neopterin and $\beta_{2^{-}}$ microglobulin are early predictors of AIDS. In: Kahn N, Melnick JL, eds. Monographs in virology: human immunodeficiency virus. Basel, Switzerland: Karger, 1990;18:6!-73.

9. Brookmeyer R, Gail MH. Biases in prevalent cohorts. Biometrics 1987;43:739-49.

10. Rosenberg PS, Biggar RJ, Goedert JJ, et al. Backcalculation of the number with human immunodeficiency virus infection in the United States. Am J Epidemiol 1991;133:276-85.

11. Preble OT, Black RJ, Friedman RM, et al. Systemic lupus erythematosus: presence in human serum of an unusual acid-labile leukocyte interferon. Science 1982;216:429-31.

12. Kaplan EL, Meier P. Nonparametric estimation from incomplete observations. J Am Stat Assoc 1958;53:457-81.

13. Cox DR. Regression models and life-tables. J R Stat Soc 1972;34:187-220.

14. Rabkin CS, Goedert JJ, Biggar RJ, et al. Kaposi's sarcoma in three HIV-1-infected cohorts. J Acquir Immune Defic Syndr 1990;3(suppl 1):38-43.

15. Krown SE, Niedzwiecki D, Bhalla RB, et al. Relationship and prognostic value of endogenous interferon- $\alpha, \beta_{2}$-microglobulin, and neopterin serum levels in patients with Kaposi sarcoma and AIDS. J Acquir Immune Defic Syndr 1991;4: 871-80.

16. Eyster ME, Goedert JJ, Poon M-C, et al. Acidlabile $\alpha$-interferon: a possible preclinical marker for the acquired immunodeficiency syndrome in hemophilia. N Engl J Med 1983;309:583-6.

17. Melmed RN, Taylor JM, Detels $R$, et al. Serum neopterin changes in HIV-infected subjects: indicator of significant pathology, CD4 $\mathrm{T}$ cell change, and the development of AIDS. J Acquir Immune Defic Syndr 1989;2:70-6.

18. Hofmann B, Wang $Y$, Cumberland WG, et al. Serum $\beta_{2}$-microglobulin level increases in HIV infection: relation to seroconversion, CD4 T-cell fall and prognosis. AIDS 1990;4:207-14.

19. Sönnerborg AB, von Stedingk L-V, Hansson L-O, et al. Elevated neopterin and $\beta_{2}$-microglobulin levels in blood and cerebrospinal fluid occur early in HIV infection. AIDS 1989;3:277-83.

20. Krämer A, Biggar RJ, Goedert JJ. Markers of risk in HIV-1. N Engl J Med 1990;322:1886.

21. Schechter MT, Craib KJP, Le TN, et al. Susceptibility to AIDS progression appears early in HIV infection. AIDS 1990;4:185-90.

22. Fuchs D, Hausen A, Reibnegger G, et al. Neopterin as a marker of cell-mediated immunity: application in HIV infection. Immunol Today 1988;9:150-5.

23. Berggard I, Bearn AG. Isolation and properties of a low molecular weight microglobulin occurring in human biological fluids. J Biol Chem 1968;243: 4095-5103.

24. Epstein LB. The comparative biology of immune and classical interferons. In: Cohen S, Pick E, Oppenheim JJ, eds. Biology and the lymphokines. New York: Academic Press, 1979:443-514.

25. Revision of the CDC surveillance case definition for acquired immunodeficiency syndrome. MMWR 1987;36:3S-14S.

26. Redfield RR, Wright DC, Tramont EC. The Walter Reed staging classification for HTLV-III/LAV infection. N Engl J Med 1986;314:131-2. 